\title{
BIJDRAGE TOT DE GESCHIEDENIS DER KARO-BATAKSTAMMEN.
}

DOOR

J. H. NEUMANN;

II.

(Vervolg op Deel 82, pag. 1.)

Meende ik met mijn vorige bijdrage bovenstaand onderwerp vrijwel uitgeput te hebben, de hieronder volgende verrassende ontdekking, heeft weer nieuwe perspectieven geopend en de hoop verlevendigd, dat er nog wel meer te voorschijn zal komen.

Eenigen tijd geleden gaf ik in druk een Poestaka Ginting (Beroe Rengga Koening ras Poestaka Ginting, verkrijgbaar bij het Lectuur en Leermiddelenfonds te Sibolangit, O. K. van S.) Dit was de eerste poestaka door mij ontdekt met historische bijzonderheden. Of dit nu een prikkel voor de anderen geweest is om ook een poestaka van hun stam te bezitten ? Het is mogelijk. Althans onze evangelist $\mathrm{Pa}$ Belat, werkzaam in Boven-Langkat, verraste ons met een afschrift van een Poestaka Kembaren. Deze poestaka was in het bezit van den pengoeloe van Sapo Padang, een dorp gelegen in Boven-Langkat, een goede dagmarsch boven Bohorok.

Dit gewichtige document, dat ik in afschrift ontving, geef ik hier precies zooals het afschrift luidt. De interpunctie van $\mathrm{Pa}$ Belat was af en toe niet te volgen om een dragelijke zin te krijgen, dus verbeterde ik die hier en daar. Over het algemeen is de taal de KaroBataksche, met enkele dialectische afwijkingen. Trouwens het dialect van de Kembaren wijkt ook hier en daar van het Karosch der Hoogvlakte af. Zoo schrijft hij goelar voor gelar, doengkoeh voor dengkeh, $n d \bar{e}$ voor $d \bar{e}$ of adi. Verder wordt in enkele woorden de verwante neusklank weggelaten, zoodat hij takoeh voor tangkoeh schrijft. Dit zal voor den het Karoosch machtige geen beletsel zijn het verhaal te lezen. Bij de vertaling heb ik mij meer op den zin, dan op een 
letterlijke weergave toegelegd. Waar geen goede zin te krijgen was, plaatste ik een noot in den tekst, of een vraagteeken. De mondeling verstrekte inlichtingen plaatste ik hier en daar er tusschen.

Hier volge tekst en vertaling van de

\section{Poestaka Kembaren.}

Lit me ndoebē anak Pagaroejoeng doea semboejak, doea nandē; sintoea tading Pagaroejoeng, si ngoeda lawes ngkelēweti poelo Pertja ēnda, renen inganna, iban ia dengnga djelma ibas poelo Pertja ēnda. Amin empak apa pē lawes, ibabana nge tjat(tjap?) soerat keradjān, tjap si siwah, piso bala bari, piso keradjān, si berēken kakana ndoebē. Roesoer nenna inganna, langnga ia djoempa bagi oekoerna tengteng; si kitik, kitiksa, si mbelin, mbelinsa. E makana seh ia Bangko, redagang ia i Bangko, empat kalak, ndapeti ia doea kalak, erdjoema-djoema ia i Bangko. Enggo tjoekoep sinoean-sinoeanna: „Koega pa kita ēnda radja ?” nina ginemgemna si lima kalak. „Metoenggoeng me koeta, diberoe sopē lit.” Toehoe, atē radja. Maka nisiapna perahoena, makana relajar me ia toe Makkah. Maka djoempa ia diberoe, maka iteboesina diberoe sisipoeloesa. Maka nibabana toe Bangko, maka igenepkenna ternogal sada silima kalak. Tading bana enem.

Lit doea tahoen i Bangko, toeboeh anakna ternongal sada anakna, anakna pelin-pelin dilaki. Maka lit teloe tahoen, noengkoen ginemgemna toe radja Bangko: „Radja! Adi la kam pagi idjēnda, nterem anakndoe, apai radja kami ?" Toehoe, atē radja; iban djelma roetangroetang nandēna iteboesina; radja ndoebē nandēna. Si enem è lahang. Maka isiapna me perahoena, relajar radja Bangko toe taneh Radja Koeala Ajer Batoe.

Ban èdi radja mbēlin, djē ia empoina anak radja. Lit satahoen maka moelih ia toe Bangko, ibabana anakna dilaki. Itaroehken mamana.

Lit satahoen ia i Bangko, noengkoen rajatna: „Radja: ndē lawes kamoe pagi, apai radja kami ?" E maka poeloeng radja me si ngeranana, poeloengna anakna kerina. E maka toeriken bapana me katana : ,ēm kēna enem si mbelinna”, nina bapana, „,ndē radja, radja nge kēna kerina. Tapi tjap keradjān ibas ingan tjap keradjan tjap si siwah, tjap piso bala-bari keradjān bas si kitik ēnda, ban ia beberē radja. Oela ko pagi erlawan", nina bapana petangarkenna toe si ngerana. „Ndē bagē nindoe, bapa, isē ngelawan katandoe ?”

Seh satahoen sada, matē bapana. Makana niatoerken beras, kerbo 
singerana, si tangdingken bapana ndoebē. Makana nitangkoehken si ngeranana si tangkoehken bapana ndoebē, ban bana tjap keradjān, ban anakna si beberē radja Koeala Ajer Batoe. Ngelawan si enem.

Reh tahoenna sada tangkoehkenna ka. Ngelawan si enem. Dem empat kali itangkoehken beberē radja. Roesoer ngelawan anak si enem.

E maka piah reh Keramat Kerangen nari, nggedang-mbelin, maba toengkatna, padjekkenna kesajan, lawes ia toe roemah, soengkoenina radja. La lit. Soengkoenina toeri-toerinna. Patoet nge sibeberē radja radja. Ngelawan anak si enem. „Lengleng doni”, nina Keramat. „Lengleng, lengleng, nina si enem. Lawes keramat, tjaboetna tongkatna. Lawes ia, loewar lajo sarah lobang tongkatna, lengleng me toehoe.

Siapna me perahoe si beberē radja, babana toe roemah, tamana erta-ertana djē ras tjap keradjān, tjap siwah, tjap piso bala bari keradjān. Lajarkenna perahoena si Alas, tangkoeh ni Alas. E maka ibanna djoemana, djadi koeta tergelar Ketangkoehen, ia lebē-lebē toe laoe Alas manoesia. E maka ia empo. Toeboeh anakna doea. E maka pijah mbelin anakna. Matē bapana. Bapana radja Bangko, beberē radja Koeala Ajer Batoe.

E maka lawes si ngoeda, babana tjap soerat keradjān, tjap si siwah. Tadingkenna tjap piso bala bari keradjān man si ntoea. Lawes si ngoeda ibabana ginemgemna toe laoe Petani, ban ia lebē mantek koeta ngaloer-ngaloer Laoe Petani Mabar, anak si ngoeda.

Anak si ntoea tading ni Alas, radja Ketangkoehen. E maka reh djelma sada Kabangken Lajang-lajang, ndaboeh ni Alas. Djoempa radja Ketangkoehen. Babana toe roemah, mehoeli lagoena, semboejak banna bana. E maka empo radja Ketangkoehen, toeboeh anakna, doea dilaki. Pegantji-gantji radja. Maka piso keradjān ras si Kabangken lajang-lajang. Sidang man si Kabangken lajang-lajang piso keradjān.

Matē bapana. Pindo anak radja piso bapana. La ia nggit si Kabangken lajang-lajang merekēntja. Djadi-djadi me pengoeloe si Kabangken lajanglajang, ban piso radja Bangko nge. Mesoei atē anak radja. „Djēnda kam”, nina si ntoea, ,pindo pisonta man pengoeloe, lawes akoe toe Teba, ndahi seninanta si enem", nina empak agina.

Nggo lawes ia toe Teba ndahi seninana si enem. Dapetina nggo djadi radja Teba Selaki. Maka tergelar Teba Selaki: Oeis Teba mahantja ia la matē. Lit anakna, banna koetana Paropo. Mbelin anakna lawes ka ia toe Pakpak, ndahi senina si enem. Dapetina nggo djadi radja Pakpak. Maka tergelar Pakpak empak-empak ndoebē 
tjelampongna. Koetana Martogan. Empo anakna si enem, banna koetana Martogan. Empat naring kentja nggeloeh, anak si enem ndoebē. Empatna djoempasa. E maka ia empo ka. Doea kali ia enggo empo, la lit anakna dilaki.

Anak Radja Ketangkoehen nari empat, si ntoea naring, sada si ngoeda. E maka matē bapana. Mbelin anakna, anak si ngoeda la tergeloehisa bana. E maka lawes toe djahē-djahē.

Seh ia djahē-djahē banna koetana tepi-tepi Laoe Biang, kawes kahē-kahē retapinken Laoe mbelin. Padjekna berē-berēnna pengoeloe balang, Adji Manēring, sembahenta. Maka tergelar koetana ngesahkentja radja Pertibi. Ia lebē-lebē bengket ngaloer-ngaloer Laoe Bijang. E maka ia empoina beroe Ginting. Reh tahoenna doea, maka niempoina beroe Djamboer Beringin, anak Radja Koeta Roeloeh.

Reh tahoenna sada, reh moesoeh pitjet. Maka nilegina seninana si empat toe Martogan. „O kaka”, nina empak kakana, ,di la kin mēla soeroeng me tading Pertibi, ban moesoeh", nina toe kakana. „Di bagē nindoe, lawes kita”, nina kakana, pengoeloe Martogan. Ngikoet teloe kalak kakana si empat. Seh ia radja Pertibi, koeta agina: „O kaka, kai atoeren?” „Boedjang-boedjang si pitoe. Soeroeh noerih bengkoeang, pepoeloeng doerina”. „Nggo poeloeng doerina”. „Tanggerken belanga kawah, tama ipoeh si bolar oelasi doeri bengkoeang". Tama Peroemang pengelimoenen. Tjirtjir Perminak sagi doeri bengkoeang kelēwet moesoeh.

Terang oeari, boekaken moesoeh. E maka loear moesoeh. Asa pa loear, asē kena ; asa pa kena, asē matē. Taloe moesoeh. Doeng lengnga moesoeh. Ndē djē dengnga pengoeloe Martogan, la pang moesoeh merangsa Pertibi. Mbiar ia ban sada Peroemang, sada Perminak sagi, sada Pengeltep pengoeloe Martogan. Pengoeloe Pertibi la pang itadingken kakana pengoeloe Martogan. Reh tahoenna doea lengnga kang doeng moesoeh. Ndarami pengoeloe Pertibi diberoe empōn pengoeloe Martogan, penagangina. Soengkoenina si ntoea, ia la pet diberoe manoesia, ban ia peroemang. E maka isoengkoenina Perminak sagi. Mberat-berat katana. Nipempo pengoeloe Pertibi, ban mbiar tadingken kakana.

Ban Perminak sagi, lawes ia toe djoema, ban pagē mbages, megasgas oeili. Mān si karabenna: ,lawes akoe toe djoema moero oeili. Sibar tjiger pagi akoe toe roemah", nina empak toekoermasna. Lawes ia toe djoema salih djadi harimo. Seh lingē, toe djoema toekoermasna, embahken nakan. Seh ia i djoema, nenna sapo, la ia sapo. Ikoetkenna toe doeroe djoema, djoempa ia harimo, pān harimo, besoer mān. 
Lawes ia toe roemah enggo djadi djelma. Ninenna toekoermasna, enggo toe djoema", nina kalak. Ikoetkenna toe djoema, ikoetkenna toe doeroe, enggo matē. Lawes ka toe roemah : „O agi, nggo pengindo sirang siboejak. Maka bagē ningkoe: enggo kakandoe matē koeboenoeh. La goenana akoe roemah. La kalak tek enggo gia akoe salih. Labo akoe megasgas toe manoesia. Ndē toemboek pagi gatipna, adi pagi gelarna Harimo Kembaren, pantangenndoe, agi !"

Nina empak agina si Djagat, pengeltep: „Ndē bagē nina seninanta, akoe pē lawes me lah toe deleng, enggo pengindo". Nina Peroemang: Empat ndoebē semboejak sada nandē, sada tading Martogan, sada tading Pertibi, sada djadi harimo, sada djadi Oemang. Ndoebē ipindo, gendoari nibaba, agingkoe". Enda kam doea ras seninanta si Pertibi ēnda, ola sirang. Enggo keri adjar. Maka lawes ia toe kerangen peroemang, perminak sagi. Tading doea Pertibi.

Beroe Djamboer Beringin la erpemoepoes, toekoermas pengoeloe Pertibi, roesoer nggergē. Si Djagat pē aroe dengnga atē pengoeloe Pertibi lawes. „Enggo labo bagē kaka! Kamoe naring merē nakansira agindoe siberoe Djamboer Berigin. La nai akoe ngasoep merēsa. Ndē nioelihken tjēda, ndē kam merē nakan-sira. Edi enggo koeteh oetangkoe man kalimboeboe". Nina pengoeloe Pertibi pak kalimboeboe: „Djamboer Beringin ijanken si Djagat, diberoena pengoeloe Pertibi”. ,E maka enggo kita semboejak”, nina pengoeloe Pertibi pak si Djagat.

E maka lit keradjān pengoeloe Pertibi ngalokentja, ban ia lebē mantek Pertibi. E maka mentas kerbo Alas nari pengoeloe Pertibi ngaloken tjoekē taneh, sabap ia anak, ia anak sintoea. „Maka ola roebat sarah poedi atēkoe", nina pengoeloe Pertibi. E maka ,entah enterem pagi koeta maka ola roebat arah poedi karina", nina pengoeloe Pertibi. Sabap enggo man si Djagat Beroe Djamboer Beringin, toekoer man (mas ?) pengoeloe Pertibi. Sabap mbelang moesoeh maka man si Djagat, maka oela lawes atē pengoeloe Pertibi. „E maka enggo kita semboejak hingga Pertibi".

Reh tahoenna empat sikoel taloe Koeta Boeloeh perang moesoeh. Maka reh moesoeh, sabap enggo erdemoe ras Pertibi. Sikel taloe kesajan Koeta Boeloeh. E maka: „djē djangkoe ēnda la goenana”, mēla atē pengoeloe Koeta Boeloeh. E maka dahina silihna si Djagat toe Pertibi. Djoempa ia ras silihna. „O silih”, nina pengoeloe Koeta Boeloeh pak silihna si Djagat. „Ndē la atēndoe mekoeah, soeroeng me tombang Koeta Boeloeh”. „Ndē bagē nindoe silih, lawes kita”, nina silihna si Djagat. E maka lawes silihna si Djagat ras toekoer- 
masna Beroe Djamboer Beringin toe Koeta Boeloeh. Enggo seh Koeta Boeloeh: „Kai atoeren silih”, nina silihna pengoeloe Koeta Boeloeh. „Atoeren boedjang-boedjang si pitoe. Soeroeh noerih bengkoeang, pepoeloeng doerina, nitanggerken belanga kawah, tama ipoeh si bolar, oelasi doeri bengkoeang. Maka nitjirtjirken ni kelewet koeta”. Enggo nitjirtjir kelēwet koeta, maka niboekaken me moesoeh. Hasapa loear moesoeh, asē kena; asa pa kena, asē matē. Maka taloe me moesoeh doeng lengnga kang. $\mathrm{E}$ maka la bantji moelih silihna si Djagat, maka reh tahoenna doea, ibahan silihna si Djagat koetana Nggalam.

Maka toeboeh anak dilaki. Maka nitenahken silihna radja Koeta Boeloeh. E maka reh silihna toe Nggalam. Lit ia doea berngi 'ni Nggalam. „Sibaleng lah taneh ēnda, maka ola pagi roebat anak arah poedi", nina silihna pengoeloe Koeta Boeloeh nandangi silihna si Djagat. „Bagē kin nindoe, bagēe”, nina silihna si Djagat, erkata nandangi silihna Radja Koeta Boeloeh, ketoeroenen Soeka Tendel nari. E maka : „reh kamoe pagi”, nina radja Koeta Boeloeh. E maka reh silihna si Djagat, ngadi ia ni sembah, iban ēdi berē-berēnna.

E maka dapeti radja Koeta Boeloeh. E maka ,rebalengbaleng ta”, nina radja Koeta Boeloeh nandangi si Djagat. E maka toedoehken silihna si Djagat baleng aloe oeltep, dapetkentja sembah; dapetkentja Nggalam, teroes toe Laoe Boeridi ikoet kahē-kahē, seh toe Laoe Biang ikoet kahē-kahē, Damak oedjoengna. „Tanehkoe”, nina silhna si Djagat nandangi silihna radja Koeta Boeloeh. Maka nikawatkenna kawes kahē-kahē teroes koe Lawet, teroes koe Tangkoehen. E maka itjibalkenna oeltepna. E makana nitoedoehken silihna Koeta Boeloeh sarah toedoehken silihna ndai kang, toedoehken koe Laoe Biang ikoetkenna kahē-kahē, teroes koe lawet, arah kemoehoen kahē-kahē. „Tanehkoe, darat si ga toerdoengkoeh sora bedilkoe ēnda silih”, nina radja Koeta Boeloeh nandangi silihna si Djagat. E maka toelkasna boedilna ndarat. E maka moelih radja Koeta Boeloeh toe koetana. Moelih si Djagat toe Nggalam.

Reh boelanna sada, è maka retenah si Djagat toe Koeta Boeloeh: „Goelar boeboerēndoe”, nina silihna si Djagat mpak pengoeloe Koeta Boeloeh. Maka nigoelar mama pengoeloe Koeta Boeloeh moegoelar boeboerēna si Boelang Keradjān. „Maka si Boelang Keradjān pē ningkoe, iban Radja kam Bangko, koetoeroenen Radja Pagaroejoeng nari. Iban radja kam ni Alas, ban Radja kam ni Mabar, Radja kam ni Toemba, Radja kam ni Toemba, Radja kam ni Pakpak, 
Radja kam ni Poertibi, toeroes toe lawet Radja kam". Koeta Boeloeh ēnda. E maka si Djagat toehoe bapa si Boelang Keradjān.

„Ndē bagē boelangna koeradjānkoe, pintoer koealoken tjoekē Koeala, ndē koeijani Koeala”. „Pintoer”, nina radja Koeta Boeloeh. „Ndarat dantji, dijani si Djagat”. „Pintoer”, nina radja Koeta Boeloeh. ,Ndē ndarat, kai kin man alōnken ?” „Koeda, kerbo, sangkar moentas sarah tanehta ēnda, dē adi koeradjat goelarna", nina pengoeloe Koeta Boeloeh. E maka inganna ngalokentja Pertibi, iban èdi taneh si ntoea. Asa pa koeda, kerbo, sangkar mentas, ialoken bapa Boelang Keradjān.

Maka toeboeh anakna enem. Sada toe Soengkoen Berita. Sada toe Laoe mbentar. Sada toe Sampē Raja. Teloe. Lawes toe Djoeng Deleng. Sada toe Boetoe Mamak. Sada toe Koeroeas, maka koe tampē-tampē Laoe Ntēbah. Ibahanna djoemana, padjekna sapona, taroemna padang. Djadi-djadi me koeta, maka toergoelar Sapo Padang. Lid sada soendoet toeboeh anakna teloe dilaki. Si ngoeda toe Koeta Kelangē, sintengah toe Koeta Tjih. Sintoea tading i Sapo Padang. Lit sada soendoet, doea soendoet, toeboeh anakna enem, sada toe deleng Siloekoeten. Sada toe Toelodeh, sada toe Batoe Katak. Teloe tading Sapo Padang, sada anak sintoea, sada anak sintengah, sada anak si ngoeda. Anak sintoea sada dilaki. Anak di ngoeda doea dilaki. Matē anak sintoea, la lit nadingken anak dilaki; si doea matē sintoea. Doea anak dilaki, matē sintoea, tading si ngoeda. Ijankenna toekoermas kakana si la nadingken anak dilaki. Ipoepoesna anak dilaki sada. E maka ijankenna toekoermas kakana, sada ka anakna, anak dilaki, bas toekoermasna si ndoebē sada.

\section{Bilang - bi lang.}

Bilang-bilang kin alim, lako nitabah mama anak Soembiring moergana, boeboerē radja Koeala Ajer Batoe, si toergoelar Koentja tampē Koeala, radja Ketangkoehen, si ngaloer laoe Alas.

Aminna mboeē pē djelma nggeloeh la lit si bagi koeradjangenkoe ēncla. $\mathrm{Dja}$ pa la bagē ningkoe: ingan toeboeh Koeala Ajer Batoe, lawes ndoebē toe taneh Bangko, taroehken radja Koeala Ajer Batoe, langnga ndoebē beloeh dagingkoe baba. Niberēken bapakoe tjap kiniradjān Pagaroejoeng nari, tanda djelma radja. Maka tandai radja tanda radja Pagaroejoeng. Enggo tandai radja Koeala Ajer Batoe, nina ndoebē bapangkoe, toeroenen Pagaroejoeng nari, radja Bangko.

Djē maka matē bapa, sopē kang akoe mbelin, la siadjaren se- 
mboejak. Lengleng taneh Bangko. Lit perahoe tadingkoen bapa, boengkoet akoe, djē boengkoet rajat. Tangkoeh ni Alas, maka toergoelar Koetangkoehen. Maka akoe radja Ketakoehen. Enda doea anak dilaki, tah matē gia akoe, ēnda me koetoeriken koe toeroenen poerdalinkoe, sirangen djelma semboejak. Edi adjarkoe man ikoeten kalak si poedi. Seh koe ginargarkoe si poedi. Maka ndekah pē djoelma sirang semboejak roesoer la si boetoehen. Ola loepa nina pak anakna si doea. Edi katangkoe bandoe, nina mama anak Soembiring moergana, boeboerē radja Koeala Ajer Batoe, si tonggal soemboejak, si daoeh poerdalin nandangi Koetakoehen ēnda, si ngoeradjai taneh Koetakoehen, si ngaloer-ngaloer Laoe Alas.

\section{Vertaling.}

Er waren vroeger lieden van Pagaroejoeng, twee broeders, van twee moeders. De oudste bleef te Pagaroejoeng, de jongste ging het eiland Sumatra omreizen, om een woonplats te zoeken, vanwege hij nog de (eenige) mensch op Sumatra was. Waar hij ook heenging, hij voerde met zich mede de rijksbrief met negen zegels, en het mes bala bari, het rijksmes, dat zijn oudere broeder hem vroeger gegeven had.

Steeds zocht hij naar een woonplaats, nog steeds had hij er geen aangetroffen naar zijn zin Als het een kleine plaats was, was die te klein, als het een groote plaats was, was die te groot. Zoo kwam hij te Bangko, woonde daar met zijn vieren als vreemdeling, trof er twee menschen aan, hij legde rijstvelden aan te Bangko. (Dit is niet erg duidelijk, want er is niet vermeld dat hij met vier menschen op reis ging). Toen er van alles voldoende geplant was: „Hoe is het met ons gesteld o vorst ?” zeiden zijn vijf onderdanen. „Het dorp is in orde, maar de vrouwen ontbreken nog”. „Dat is zoo”, dacht de vorst. Hij maakte zijn boot gereed en zeilde naar Makkah. Hij vond vrouwen en kocht er elf los. Hij bracht ze naar Bangko, en gaf aan elk van de vijf mannen een vrouw; bleven er zes voor hem.

$\mathrm{Na}$ twee jaar werden hem in Bangko van elke vrouw een zoon geboren. $\mathrm{Na}$ drie jaar vroegen de onderdanen aan radja Bangko: .O vorst, indien ge later niet hier zijt, en uwe kinderen zijn vele, welke is dan onze vorst ?” „Dat is zoo”, dacht de vorst; omdat hunne moeders slavinnen geweest waren, door hem gelost. Zijn eigen moeder was van vorstelijke afkomst geweest, die zes niet. 
Hij maakte zijn boot gereed en radja Bangko zeilde naar het land van radja Koeala Ajer batoe. Omdat dit een groot vorst was, huwde hij daar een vorstendochter. $\mathrm{Na}$ een jaar keerde hij terug naar Bangko, met zich medebrengende een zoon. Zijn schoonvader begeleidde hem. (Waarom dit zoo van gewicht geacht wordt, dat het ook in de hierachtervolgende zang nog eens vermeld wordt, weet ik niet).

Toen hij een jaar te Bangko was, vroegen zijn onderdanen : „Indien gij te eeniger tijd weggaat, wie is dan onze vorst ?" Toen vergaderde de vorst de sprekers en al zijn kinderen. (Wie die "sprekers” zijn is niet duidelijk, het lijkt mij een titel te zijn, misschien de anak-beroe-senina bij de Karos). Toen vertelde hun vader en zeide: „Gij allen die de grootsten zijt, gij zijt allen vorsten. Maar het rijkshewijs, nl. (de brief) met negen zegels en het mes bala bari, zal bij deze kleine berusten. Want hij is van moederszijde van vorstelijke afkomst. Gij zult hem niet weerstreven": zeide hun vader. (Wat bala bari beteekent is moeilijk te zeggen. Bala kan een oud voorvoegsel zijn in het Karosch, zooals in balagais, balagēgē enz. Verder ook „krijgsman, leger”. Bari beteekent „koud, kil”. Dit is echter een andere ,koude” dan uitgedrukt wordt door malem, dat ook „koud” en tevens ,gezond”, beteekent. Niet onmogelijk is het, dat in een mij onbekend dialect bari dezelfde beteekenis heeft als malem en dan zou bala bari een mooie naam voor zulk een mes kunnen zijn zoodat het geluk aanbracht). Hij nam de sprekers tot getuigen van zijne woorden. „Indien gij aldus spreekt, o vader, wie zal zich tegen uwe woorden verzetten ?"

$\mathrm{Na}$ verloop van een jaar stierf de vader. De sprekers regelden den maaltijd uit de nalatenschap van den vader en verhieven als vorst dien de vader reeds als vorst verheven had, omdat hij bezat de rijksbewijzen, omdat hij van moederszijde afstamde van de vorst van Koeala Ajer Batoe. Het zestal verzette zich er tegen. Na een jaar verhief men hem weer als vorst, weer verzette zich het zestal er tegen. Volle vier maal verhief men hem als vorst, maar het zestal verzette zich steeds. Eindelijk kwam Keramat-uit-het-bosch, lang en dik, bracht zijn stok mede, en stak dien op het dorpserf in den grond. Hij ging naar het huis en vroeg naar den vorst. Er was geen vorst. Hij vroeg naar de reden. „Het is recht dat die van moederszijde vorst is de vorst zij”. Het zestal verzette zich. „Dan zal de zondvloed komen”, zei de Keramat. „Laat de zondvloed komen”, zeide het zestal. (Ik vertaal steeds ,, het zestal”, wellicht zal later blijken dat dit zestal een bepaalde beteekenis heeft). 
De Keramat vertrok, trok zijn stok uit den grond, en ging heen. Er kwam water uit het gat dat de stok gemaakt had, de zondvloed kwam werkelijk. De zoon van vorstelijke afkomst van moederszijde maakte zijn boot gereed, stuurde die naar het dorp, deed er zijn kostbaarheden in met de rijksbewijzen, en zeilde naar de Alaslanden en kwam aan in Alas.

Hij legde daar rijstvelden aan, daar ontstond het dorp Ketangkoehen. Hij was de eerste mensch die de Alasrivier bevoer (?) Toen trouwde hij, er werden hem twee kinderen geboren. Die kinderen waren eindelijk groot geworden. De vader stierf, de vorst van Bangko die moederzijds van den vorst van Koeala Ajer Batoe afstamde.

De jongste zoon ging op reis, hij voerde de rijksbrief mede; het mes bala hari liet hij achter. De oudste zoon ontving het rijk. De jongste zoon ging heen en bracht zijn onderdanen tot aan de Petanirivier. Hij was de eerste die het dorp Mabar langs de Petanirivier gesticht heeft. (Er is thans een onderneming Mabar, gelegen tusschen Medan en de zee. Dan zou de Petanirivier de Delirivier zijn. Vergelijk deel 82 pag. 31 waar iemand van de Tarigenstam het dorp Alē Deli moet gesticht hebben. Dit kwam dus meer voor).

De oudste zoon bleef in Alas en was radja te Ketangkoehen. Er kwam iemand die door een zwaluw gebracht werd, welke neerviel in Alas. Radja Ketangkoehen ontmoette hem en bracht hem naar zijn huis. Zijn gedrag was goed en de vorst nam hem als broeder aan.

De vorst van Ketangkoehen trouwde: twee zonen werden hem geboren. Om beurten waren zij vorst. (Wie ? De twee kinderen of de vorst en de zwaluwman ?) Het rijksmes was bij den Zwaluwman. De vader stierf. De vorstenkinderen vroegen het rijksmes van hun vader. De Zwaluwman wilde het niet geven. De Zwaluwman werd pengoeloe, vanwege het bezit van het mes van den vorst van Bangko. (De Zwaluwman wordt hier niet betiteld als ,radja”, maar als „,pengoeloe”. Radja is een titel die stellig van buitenaf ingevoerd is).

De vorstenzonen leden zeer daaronder. „Blijf gij hier”, zeide de oudste, vraag ons mes aan den pengoeloe. Ik ga naar Toba om onze broeders, het zestal, te bezoeken". Zoo zeide hij tot zijn jongere broeder.

Hij ging naar Toba zijn broeders, het zestal, bezoeken. Hij ontmoette ze. Ze waren reeds vorst geworden van Toba Selaki. Dat het Toba Selaki heet (is daarom): Het Tobasche kleed had gemaakt dat ze niet omgekomen waren (nl. in den zondvloed. De eigenaar van 
de poestaka verklaarde dit aldus: Bij het drijven op het water was het Tobasche kleed hol gaan staan en aldus dreven zij veilig naar de droge plaats.) Hij had een zoon en maakte voor hem het dorp Paropo. (Beide dorpen liggen aan de westzijde van het Tobameer). Toen zijn zoon groot was, ging hij naar Pakpak, om zijn broeders, het zestal, te bezoeken. Hij vond ze, ze waren reeds vorsten van Pakpak geworden. Dat het Pakpak heet komt van ,spaanders van de boomstam". (Tjelampong moet beteekenen een boomstam of stuk hout, waar men zich aan vast houdt om drijvende te blijven. Deze broeders waren dus ook uit den zondvloed gered door zich aan een stuk hout vast te houden, zooals de andere door hun kleed).

Hun dorp was Martogan. De kinderen van het zestal trouwden en (hadden) het dorp Martogan gesticht. Vier van het zestal leefden nog maar. Het viertal ontmoette hij. Hij huwde weer. Twee maal was hij reeds gehuwd maar had geen zonen.

De kinderen van den vorst van Ketangkoehen waren vier nog. De oudste was nog in leven en de jongste. Toen stierf hun vader. Toen zijn kinderen groot waren, was de jongste niet in staat voor zich zelf te zorgen. Hij ging naar de Benedenlanden (Djahē-djahē. waar dit land van uit de Alaslanden te zoeken is wordt straks vermeld. Hier is zeker alleen bedoeld dat hij stroomafwaartsch ging). Toen hij in de benedenlanden was, maakte hij een dorp aan de Bijangrivier, (de Wampoe), links stroomafwaarts, met als badplaats de rivier, stichtte een pengoeloe balang, adji manēring (de vorst die omziet), onze plaats van aanbidding. (Laoe mbelin vertaalde ik hier met ,de rivier”, er is daar echter ook een rivier die Laoe mbelin heet. Een pengoeloe balang is een beeldje van steen, dat het dorp bewaakt. Bij het naderen van onheil geeft het geluid. In de buurt van het dorp Goenoeng Meriah, niet te verwarren met G.M. in Serdang gelegen, staan nog eenige kleine beeldjes, en heet de offerplaats van het dorp nog Silän Manēring). Zijn dorp heette om te bevestigen dat hij vorst was, Pertibi. (Thans is het dorp verlaten). Hij was de eerste die het stroomgebied van de Bijangrivier betrad. Hij huwde met een meisje van den Gintingstam. Na twee jaren huwde hij met een meisje van de Djambeer Beringinstam, dochter van den vorst van Koeta Boeloeh.

$\mathrm{Na}$ een jaar ontstond een benauwende oorlog. Hij ging zijn vier broeders van Martogan halen. „O oudere broeders”, zeide hij tot zijn oudere broeders, ,,indien gij niet beschaamd zijt dat het dorp Pertibi verlaten moet worden, vanwege den vijand", zeide hij tot 
zijn oudere broeders. „Indien gij aldus zegt, laten we gaan”, zeiden zijn oudere broeders, de pengoeloes van Martogan. Drie broeders uit het viertal volgden hem. Ze kwamen te Radja Pertibi, het dorp van hun jongere broeder. „O oudere broeders, wat moet er gedaan worden ?” „Boedjang-boedjang si pitoe (naam van een toovermiddel). Beveel dat men bengkoeang afrisse, verzamel de dorens. $\mathrm{Na}$ de dorens verzameld te hebben, kook ze in een pan (bilanga kawah een platte ijzeren pan), voeg er het vergift si bolar bij om de dorens met gift te drenken". De Peroemang maakte het toovermiddel dat men onzichtbaar wordt (pengelimoenen). De Perminak sagi strooide de dorens om de versterking van den vijand. (Zooals naderhand blijkt is een van de broeders een oemang en de andere een weerwolf. De naam Perminak sagi is wel opvallend, gewoonlijk spreekt men van harimo sagi): Bij het lichten van den dag werden de vijandelijkheden heropend. De vijand kwam uit zijn versterkte plaats; zoovelen als er uitkwamen, zoovelen werden er geraakt; zoovelen als er geraakt werden, zoovelen stierven. Al had de vijand het afgelegd, de oorlog was nog niet uit. Zoolang als de pengoeloes van Martogan er waren, durfde de vijand Pertibi niet beoorlogen. Hij was bang, want van de pengoeloes van Martogan was er een een oemang, en een een Perminak sagi (weerwolf), en een een blaasroerschieter. De pengoeloe van Pertibi had niet den moed om zijn oudere broeders, de pengoeloes van Martogan, te laten gaan.

$\mathrm{Na}$ twee jaar was de oorlog nog niet uit. De pengoeloe van Pertibi zocht vrouwen voor de pengoeloes van Martogan om ze vast te houden. Hij vroeg aan den oudste, maar deze wilde geen vrouw hebben uit de menschen, omdat hij een oemang was. Hij vroeg den Perminak sagi. Hij had bezwaren. De pengoeloe van Pertibi deed hem (den blaasroerschieter) trouwen omdat hij bang was dat zijn oudere broeder hem verlaten zou.

Omdat hij een Perminak sagi was, ging hij naar de rijstvelden. Omdat de rijst al hoog stond en de wilde zwijnen schade aanrichtten. Tegen het avondeten: „Ik ga naar het veld om de wilde zwijnen te verjagen, tegen morgen twaalf uur kom ik naar het dorp terug", zeide hij tot zijn vrouw. (Het verhaal is hier te beknopt, bedoeld is hier de blaasroerschieter, want diens vrouw wordt later opgegeten door de weerwolf). Hij ging naar het veld en veranderde zich in een tijger. (Den volgenden dag) ongeveer om één uur, ging zijn vrouw naar het veld om eten te brengen. In het veld gekomen keek ze in de tuinhut, hij was niet in de tuinhut. Ze volgde de rand van het 
veld en kwam een tijger tegen. De tijger at haar op en verzadigde zich. Daarna ging hij naar het dorp, hij was weer mensch geworden. Hij zag om naar zijn vrouw, ze was naar het veld gegaan, zeiden de menschen. Hij volgde haar naar het veld, ging haar na naar den rand van het veld. Ze was al dood.

Hij ging naar het dorp. „O jongere broeder, het is het noodlot dat broeders scheiden moeten. Dat ik aldus spreek, is: uw oudere zuster is al dood, ik heb ze gedood. Het heeft geen nut dat ik in het dorp blijf, de menschen zullen me niet vertrouwen, al ben ik ook al in een mensch veranderd. Ik doe (anders) menschen geen kwaad. Als de strepen van den tijger aaneensluiten, dan is zijn naam arimo kembaren, dat is uw verbodsdier, zoo zeide hij tot zijn jongere broeder si Djagat, de blaasroerschieter. „Zoo spreekt onze broeder; ik ga ook maar naar het gebergte, het is het noodlot". De oemang zeide : Met zijn vieren waren we kinderen van een moeder, één bleef er te Martogan, één blijft er te Pertihi, één werd een tijger, één een oemang. Wij hebben het eertijds gevraagd (nl. ons lot aan de goden) nu moeten we het dragen. $O$ mijn jongere broeder, gij blijft met zijn tweeën te Pertibi, scheid niet van elkaar". Het gesprek is uit. De oemang en de weerwolf gingen naar het bosch, twee bleven te Pertibi. (Vele stammen onder de Karo-Bataks hebben hun verbodsdier, wellicht hun totem. Vooral de tijger is een verbodsdier. Men onderscheidt de arimo Tarigan of de a. sibero, die maar gedeeltelijk gevlekt moet zijn, en van woesten aard; daarentegen moet de arimo kembaren, wier strepen ineen moeten loopen, goedaardig zijn, en wordt niet gevreesd).

Beroe Djamboer Beringin, de vrouw van den pengoeloe van Pertibi, had geen kinderen, en klaagde haar man telkens aan (zeker omdat hij haar verwaarloosde). Ook vreesde de pengoeloe Pertibi dat si Djagat weg zou gaan. „Laat het aldus zijn, o oudere broeder, gij moet mijn vrouw nemen, ik ben niet meer in staat haar te verzorgen. Als ik haar aan haar familie terugzend, komen er onaangenaamheden, jij moet haar nemen. Ik weet wat ik aan mijn schoonvader verschuldigd ben”. En tot de schoonvader: „Djamboer Beringin zal door si Djagat tot zich genomen worden”. „Wij zijn nu echte broeders", zeide pengoeloe van Pertibi tot si Djagat”.

De vorstelijke waardigheid ontving de pengoeloe van Pertibi, omdat hij Pertibi gesticht had. Passeerden er buffels uit het Alasland, dan ontving de pengoeloe van Pertibi het uitvoerrecht, want hij was de oudste. „Opdat ze later niet zullen twisten”, zeide de 
pengoeloe van Pertibi. „Of als er later veel dorpen zijn, opdat ze later niet zullen twisten". (De weg naar Langkat liep langs Pertibi naar Bohorok).

Beroe Djamboer Beringin, de vrouw van den pengoeloe van Pertibi, was aan Djagat tot vrouw gegeven, omdat er een groote oorlog was, opdat hij niet weg zou gaan, zoo dacht de pengoeloe van Pertibi. „Wij zijn broeders hingga pertibi (??)”. Na vier jaren wilde de vijand Koeta Boeloeh ten onderbrengen. De oorlog kwam omdat Koeta Boeloeh betrekkingen onderhield met Pertibi. Hij wilde het dorp Koeta Boeloeh overwinnen. „Het is tot geen nut dat ik hier blijf", beschaamd zeide dit de pengoeloe van Koeta Boeloeh. Hij ging zijn zwager si Djagat te Pertibi bezoeken.

Hij ontmoette zijn zwager. „O zwager”, zeide de pengoeloe K.B. tot zijn zwager si Djagat, ,indien gij niet barmhartig zijt, dan gaat K. B. verloren”. „Als je zoo zegt, o zwager, laten we dan gaan”, zeide zijn zwager si Djagat. Daarop ging si Djagat met zijn vrouw beroe Djamboer Beringin naar K. B. Te K. B. aangekomen zijnde, vroeg zijn zwager, de pengoeloe van $\mathrm{K}$. B.: „Wat moet er gedaan worden ?” „De regel van Boedjang-boedjang si pitoe”. Gelast bengkoeang (een pandanus, welke men voor vlechtwerk gebruikt) af te rissen, verzamel de dorens, kook ze in een pan, doe er het vergift si bolar bij om de dorens vergiftig te maken. Strooi ze om het dorp". Men strooide ze om het dorp. De vijandelijkheden werden heropend. Zoovele vijanden uitkwamen, zoovelen werden er geraakt; zoovelen als er geraakt werden, zoovelen stierven er. De vijand legde het af, maar uit was het niet.

Zwager si Djagat mocht niet huiswaarts keeren. Na twee jaar makte zijn zwager voor hem het dorp Nggalam. Er werd hem een zoon geboren. Hij noodigde zijn zwager uit, de vorst van K. B. Zijn zwager kwam en bleef twee nachten in Nggalam. „Laten we toch de grenzen van ons land vaststellen", zei de vorst van $\mathrm{K}$. B. tot zijn zwager si Djagat, opdat onze kinderen er later niet om twistten". „Als je zoo zegt, dan zij het zoo", zeide si Djagat tot de vorst van K. B. die van Soeka Tendel afstamde (Hier moet even de opmerking gemaakt worden, dat dit niet klopt met het voorgaande. Eerst is vermeld, dat de dochter van den vorst van $\mathrm{K}$. B. een beroe Djamboer Beringin was, waaruit logisch volgt dat de merga van haar vader ook Djamboer Beringin moet zijn geweest. $\mathrm{Nu}$ is hier sprake dat hun merga Soeka tendel was. Dit is ook de merga van den tegenwoordigen sibajak. Naar men mij vertelde is de merga Djamboer Beringin 
verdwenen. Soeka tendel is een nog bestaand dorp bij den berg Sinaboen).

Kom dan morgen", zei de vorst van K. B. Zwager si Djagat kwam en wachite bij de offerplaats die hij gemaakt had tot zijn of ferplaats. Hij vond daar de vorst van $\mathrm{K}$. B.

„Laten we onze grenzen vaststellen”, zeide de vorst van K. B. tot si Djagat. Si Djagat wees met zijn blaasroer de grenzen aan van af de heilige plaats naar Nggalam, recht door tot Laoe Boeridi stroomafwaarts tot aan de Bijangrivier stroomafwaarts, Damak als eindpunt. „Dat is mijn land”, zeide si Djagat tot den vorst van $\mathrm{K}$. B. Hij zwaaide met zijn blaasroer links stroomafwaarts recht tot aan de zee, tot aan Tangkoehen. Toen legde hij zijn blaasroer neer.

Toen wees zijn zwager van $\mathrm{K}$. B. volgende de richting van zijn zwager en wees naar de Bijangrivier stroomafwaarts tot aan zee. „Rechts stroomafwaarts is mijn land, zoo ver het land in als te hooren is de knal van mijn geweer, o zwager", zeide de vorst van K. B. tot zijn zwager si Djagat. Hij schoot zijn geweer af. Toen keerde de vorst van K. B. naar huis terug. Si Djagat ging ook naar huis, naar Nggalam.

$\mathrm{Na}$ een maand zond si Djagat een boodschap aan den vorst van K. B.: „Geef een naam aan Uw neef !" En zijn oom gaf hem tot naam: Si Boelang keradjān. (Het uitgestrekte rijk). „Dat ik hem het ,uitgestrekte rijk" noem, omdat gij vorst zijt van Bangko, afstammeling van den vorst van Pagaroejoeng. Omdat gij vorst zijt van Alas, vorst van Mabar, vorst van Toemba (Tamba ?) vorst van Pakpak, vorst van Pertibi, tot aan de zee toe zijt gij vorst". Si Djagat is de vader van si Belang Keradjān. „Indien mijn rijk zoo uitgestrekt is, dan is het recht dat ik het uitvoerrecht van de riviermonding ontvange, als ik de bezitter ben van de riviermonding". „Het is recht zoo", zei de vorst van Koeta Boeloeh. „Er mag uitgevoerd worden als si Djagat het bewoond". „Zoo is het recht”, zeide vorst van K. B. „Indien uitgevoerd wordt, waarvan moet er ontvangen worden ?" Paardęn, buffels, slaven, die langs ons gebied gaan, „dē adi koeradjat goelarna (?)", zeide de pengoeloe van K. B. De plaats om de rechten te betalen is Pertibi, omdat dit het land van de oudste was. Alle paarden, buffels en slaven die voorbijgingen, daarvan ontving de vader van si Belang Keradjān (het uitvoerrecht).

(Wij kunnen niet zeggen dat deze passage erg duidelijk is. Is met koeala de riviermonding in zee bedoeld ? Of een monding van een rivier in de andere ? Gezien de mondelinge overleveringen dat de 
Perangin-angin hunne macht tot aan Bindjei hebben uitgestrekt, lieb ik aan de grensregeling gedacht ,tot aan zee". Maar later wordt Pertibi genoemd als plaats waar het uitvoerrecht moest voldaan worden).

Er werden hem (wien ? si Djagat of si Belang Keradjān ?) zes kinderen geboren. Een ging naar Soegkoen Berita, èèn naar Laoe Mbentar, èèn naar Sampē Raja, drie gingen heen: èèn naar Oedjoeng Deleng, èèn naar Boetoe (Batoe ?) Mamak, een naar Koeroeas, aan den hoogen kant van Laoe NTëbah. Hij maakte een rijstveld, maakte een tuinhut (sapo) het dak van gras (padang). Het werd een dorp, genaamd Sapo Padang.

In verloop van een geslacht werden hem drie zonen geboren. De jongste ging naar Kelangē, de middelste naar Koeta Tjih. De oudste bleef in Sapo Padang. In verloop van een, twee geslachten werden hem zes kinderen geboren. Een ging naar den berg Siloekoetan, een naar Toeladeh, een naar Batoe Katak, drie bleven er in Sapo Padang. De oudste, de middelste en de jongste. De oudste had een zoon, de jongste had twee zonen.

De oudste zoon stierf, hij liet geen zoon na. Van de twee stierf de oudste. Twee zonen. De oudste stierf, de jongste bleef over. Hij nam de vrouw van zijn oudste broer die geen zoon nagelaten had.

Hem werd een zoon geboren. Hij nam de vrouw van zijn oudere broer en kreeg weer een zoon. Een zoon van zijn eigen vrouw.

\section{ZANG.}

De woorden van den alimbast, daartoe geveld door (mij) oom uit de Simbiringstam, moederszijdsch afstammende van den vorst van Koeala Ajer Batoe, die geheeten wordt Koentja tampē Koeala, vorst van Ketangkoehen, in het stroomgebied van de Alasrivier.

Al leven er ook vele menschen

geen is er met een lot bedeeld als ik.

Dat ik zeg dat het niet zoo is :

Geboren te Koeala Ajer Batoe, ging ik

Reeds vroeg naar Bangko,

Vorst Koeala Ajer Batoe geleidde ons.

Nog was ik niet groot,

Vader gaf mij de rijkssieraden van Pagaroejoeng,

Het bewijs dat iemand vorst is.

De vorsten kenden de sieraden van Pagaroejoeng,

D1. 83. 
De vorst van Koeala Ajer Batoe kende ze, zeide eertijds mijn vader, de afstammeling van

de vorst van Bangko.

[Pagaroejoeng,

Toen stierf vader, nog was ik niet groot, broeders waren er niet om elkaar te onderwijzen.

Overstroomd werd het land Bangko door de zondvloed, Een boot had vader nagelaten,

Daar stapte ik in, daar stapten de onderdanen in.

De boot landde in Alas, geheeten Ketangkoehen.

Ik ben de vorst van Ketangkoehen.

O mijn beide zonen, 't kon zijn dat ik stierf.

Hier vertel ik an mijn afstammelingen van mijne

[reizen,

van de scheiding van menschen die broeders zijn.

Dit is mijn onderwijs dat gevolgd moet worden

door die na mij komen.

tot aan -mijn kroost dat na mij komt.

Als lang gescheiden zijn die broeders zijn weet men niets meer van elkaar.

Vergeet dit niet, zeg ik aan mijn beide zonen.

Dit zijn mijn woorden tot $\mathrm{U}$, zeg ik

die van de Simbiringstam ben, neef van den

die eenige zoon is,

[vorst van Koeala Ajer

die van verre kwam naar Ketangkoehen hier, die heerscht over het land Ketangkoehen, in het stroomgebied van de Alasrivier.

Het belang van den inhoud dezer poestaka is wel deze : dat er een schakel gelegd wordt tusschen Minangkabau en de SimbiringKembarenstam. Wij kunnen het medegedeelde in twee deelen scheiden. Een deel dat tot de vroegere geschiedenis behoort, nl. de reis van Pagar roejoeng via Bangko tot Ketangkoehen in de Alaslanden, en een tweede deel dat tot de jongere geschiedenis behoort, nl. het ontstaan van Pertibi en de vandaar uitgaande verspreiding der Simbiring-Kembaren dorpen in de streek van Liang Melas en Boven-Langkat.

Vertrokken van het hof van Pagar roejoeng, een vorstenzoon, 
maar van een andere moeder als de oudste zoon, reist hij naar Bangko, sticht daar een dorp of rijk en wordt zelf vorst. Hij heeft zeven zonen, waarvan zes van slavenmoeders en een van een vorstendochter van Koeala Ajer Batoe. Na zijn dood erkennen de zes broeders van de slavinnen den echten vorstenzoon niet. Een zondvloed verjaagt allen. Het zestal gaat naar de Pakpaklanden (volgt misschien de Renoenrivier) en wordt daar vorst. In Silahi-lahi en Paropo aan het Tobameer worden de Gintings overwonnen en heerschen de Kembaren. De echte vorstenzoon gaat de Alasrivier op en sticht Ketangkoehen. Ook daar wordt het geslacht verdrongen door de Zwaluwman; een jongere zoon sticht Mabar aan de Petanirivier en weer een andere Pertibi aan de Biangrivier. Daarmede zijn we aangekomen in den tijd dat de mondelinge overlevering nog bestaat.

Dit is in het kort de inhoud en de historische winst die de poestaka ons brengt. Toch openen deze weinige mededeelingen ons wijde perspectieven. De Simbiringstam, (de Zwarten) zijn dan uit Minangkabau afkomstig, tenminste de S. Kembaren. De Singkelrivier is dan de weg tot het Pakpak- en Karoland geweest. Van Atjeh is nog geen sprake. Later als de andere Simbiringstammen het land inkomen wel. Atjeh is dan de vijand van de Malēala enz. Hieruit zouden we dan kunnen afleiden dat Atjeh in dien tijd nog geen groote rol speelde op de Westkust, later echter wel. Het halen van vrouwen te Makkah zou weer aanleiding kunnen zijn om te denken, dat de Islam toch in de buurt zou wezen. Maar de mannen zijn dan toch geen Mohammedanen geweest.

Nog verder kunnen onze gissingen zich uitstrekken. Men kan (nu niet zonder eenigen grond) gaan denken, dat de Soemanik fvan Minangkabau, de Manik aan de Tjinendang, de Gintingmanik in het Karoland en de Damanik van Simeloengoen verwant met elkaar zijn en aan een vroegere immigratie langs de Singkelrivier denken, zoodat de Simbiring Kembaren een reeds lang gevolgde route namen. De vraag in mijn vorige bijdrage gesteld: Hoe het komt dat het KaroBataksch zulk een groote oppervlakte beslaat, zou dan eveneens beter verklaarbaar zijn. Alleen de naam Simbiring, de Zwarten, zou aan een Hindoe-Minangkabausche stam doen denken. Daarmede zou ook verklaard zijn, dat er zoovele Hindoe-elementen in de KaroBataksche godsdienstige voorstellingen voorkomen.

Waar we Bangko en Koeala Ajer Batoe te zoeken zullen hebben, weet ik niet. Mogelijk dat anderen in het hierboven medegedeelde 
aanleiding zullen vinden, hun kennis mede te deelen. Nog wil ik even wijzen op de onduidelijke passage over het bezit van Pertibi van de koeala, ,de riviermonding”. Dit kan zijn de uitmonding in een andere rivier, maar ook die in zee. Zou dit een aanwijzing kunnen zijn voor het bestaan van het Batakrijk aan de Aroebaai ? Misschien dat later ontdekkingen hier meer licht over zullen doen opgaan.

Een moeilijkheid levert de tjap si siwah op in verband met het rijk van Pagar roejoeng. Wij denken toch al heel spoedig aan de tjap sembilan van Atjeh. Het ,negental zegels” of het ,negenvoudig zegel" waarmede de brief gestempeld of waarvan de brief voorzien was, wordt hier verondersteld van Pagar roejoeng afkomstig te zijn. Hoe een en ander met elkaar te rijmen is, durf ik hier niet te beslissen. Werd te Pagar roejoeng ook een negenvoudig zegel gebruikt ?

In dit verband wil ik wijzen op het artikel van G. R. Rouffaer: De Hindostansche oorsprong van het negenvoudig Sultanszegel van Atjeh. Bijdragen deel 59, pag. 380). Daarin zegt de schrijver: „Dus: het denkbeeld der Atjehsche tjap sembilan is aan Hindostan ontleend, na $1603 . .$. . Het meest aannemelijke .... tusschen 1605 en 1627 ". Daar onze poestaka geen enkele datum geeft, zelfs geen naam, en er uit de overige gegevens niet valt op te maken dat de Islam reeds in het spel is, behalve het halen van vrouwen uit Makkah, concludeerde ik: Van Atjeh is nog geen sprake, en de S. Kembaren waren geen Mohammedanen. Later vermeldt de mondelinge overlevering dat de andere Simbirings wel door Atjeh vervolgd werden. Wij zijn dan echter in een andere periode dan toen de Kembarens het land in kwamen.

Raja, Augustus 1926 